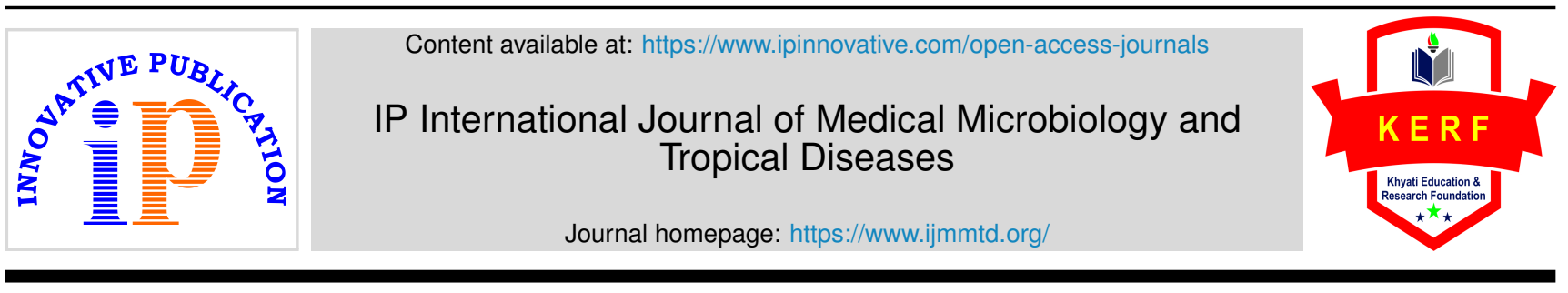

Original Research Article

\title{
Antifungal susceptibility of clinically significant candida species by disk diffusion method
}

\author{
Ajitha Reddy Edula ${ }^{1, *}$ \\ ${ }^{1}$ Dept. of Microbiology, RVM Institute of Medical Sciences \& Research centre, Mulugu, Telangana, India
}

\section{A R T I C L E I N F O}

\section{Article history:}

Received 28-04-2021

Accepted 21-05-2021

Available online 25-06-2021

\section{Keywords:}

Candida

Antifungal susceptibility

Disk diffusion method

\begin{abstract}
A B S T R A C T
Context: Antifungal susceptibility of candida.

Aims: To perform antifungal susceptibility testing on candida isolates by disk diffusion method \& study its susceptibility pattern.

Settings and Design: The present study was conducted in the department of Microbiology in a tertiary care hospital in Hyderabad from January 2013 to June 2014, with prior approval of the Institutional Ethics Committee. The present study was designed to perform antifungal susceptibility test on Candida isolates by Disk Diffusion Method and study its susceptibility pattern.

Materials and Methods: 102 Candida isolates were subjected to Antifungal susceptibility testing by Disk diffusion method using Mueller-Hinton Agar $+2 \%$ Glucose and $0.5 \mu \mathrm{g} / \mathrm{mL}$ Methylene Blue Dye (GMB) Mediumas per CLSI guidelines.

Statistical analysis used:

Results: Antifungal susceptibility test shows that C. albicans is more susceptible to all the antifungal agents tested. Resistance to azole group of drugs was more pronounced in non-albicans candida spp. Voriconazole seemed to be superior to Fluconazole with a better susceptibility in the Fluconazole resistant strains also. Conclusions: Findings of the antifungal susceptibility test suggest that Candida spp., differ in their susceptibility to antifungal agents. Antifungal susceptibility testing of Candida isolates will be helpful in guiding physicians to select the appropriate antifungal drug so that therapeutic failures can be avoided thus decreasing patient morbidity and mortality.
\end{abstract}

(c) This is an open access article distributed under the terms of the Creative Commons Attribution License (https://creativecommons.org/licenses/by/4.0/) which permits unrestricted use, distribution, and reproduction in any medium, provided the original author and source are credited.

\section{Introduction}

The Candida species are ubiquitous yeasts which are a part of normal flora of the alimentary tract of mammals and the mucocutaneous membranes of humans. ${ }^{1}$ It becomes an opportunistic pathogen as a result of one or more underlying pre-disposing factors. ${ }^{2}$ Until recently Candida albicans was the most common yeast isolated from infections. Epidemiologic data from the past decade reveal a paradigm shift in Candida infections with non -albicans Candida species such as C.glabrata, C.tropicalis, and C.krusei as emerging important pathogens. ${ }^{3-6}$ This transition has had a significant clinical impact due to decreased susceptibility

\footnotetext{
* Corresponding author.

E-mail address: ajita.b.reddy @gmail.com (A. R. Edula).
}

of these non -albicans yeasts to antifungal agents. ${ }^{5}$ Candida albicans and non-albicans species are closely related but differ from each other with respect to epidemiology, virulence characteristics, and fungal susceptibility. The Combined effects of increasing number of fungal infections, growing number of patients at risk, the increasing rate of fungal resistance, and the expanded antifungal armamentarium have led to an increased recognition of the need for standardized laboratory testing for antifungal drug susceptibility. ${ }^{7}$ Agar-based susceptibility testing methods have been focus of interest for many researchers, due to their simplicity, reproducibility and lack of requirements for specialized equipment. ${ }^{8}$ Various Indian workers ${ }^{9-11}$ used Mueller Hinton Agar supplemented with $2 \%$ Glucose and $0.5 \mu \mathrm{g} / \mathrm{ml}$ Methylene Blue Dye for Antifungal Susceptibility 
testing by Disk Diffusion Method and reported an increased resistance of non -albicans Candida isolates, to Azole group of drugs. The present study was designed to perform antifungal susceptibility test on Candida isolates by Disk Diffusion Method and study its susceptibility pattern.

\section{Materials and Methods}

The present study was conducted in the department of Microbiology in a tertiary care hospital in Hyderabad from January 2013 to June 2014, with prior approval of the Institutional Ethics Committee. A total of 102 Candida isolates from different clinical samples were processed for species identification. Candida albicans was the major species isolated followed by C. tropicalis, C. parapsilosis, C. krusei, C. glabrata and C. dubliniensis. All the speciated Candida isolates were subjected to Antifungal susceptibility testing by disk diffusion method using Mueller-Hinton Agar $+2 \%$ Glucose and $0.5 \mu \mathrm{g} / \mathrm{mL}$ Methylene Blue Dye (GMB) Medium as per CLSI guidelines. ${ }^{12}$ Antifungal disc used: Amphotericin - B (100U), Clotrimazole $(10 \mu \mathrm{g})$, Fluconazole $(25 \mu \mathrm{g})$ and Voriconazole $(1 \mu \mathrm{g}) .0 .5 \mathrm{McF}$ Farland standards was used to standardize the inoculum density. C.albicans ATCC 90028 and C. parapsilosis ATCC 22019 were used as Controls. All the culture media, Antifungal disc, and control strains were obtained from Himedia Laboratories, Mumbai.

\section{Results}

The antifungal susceptibility pattern of candida species is shown in the following table.

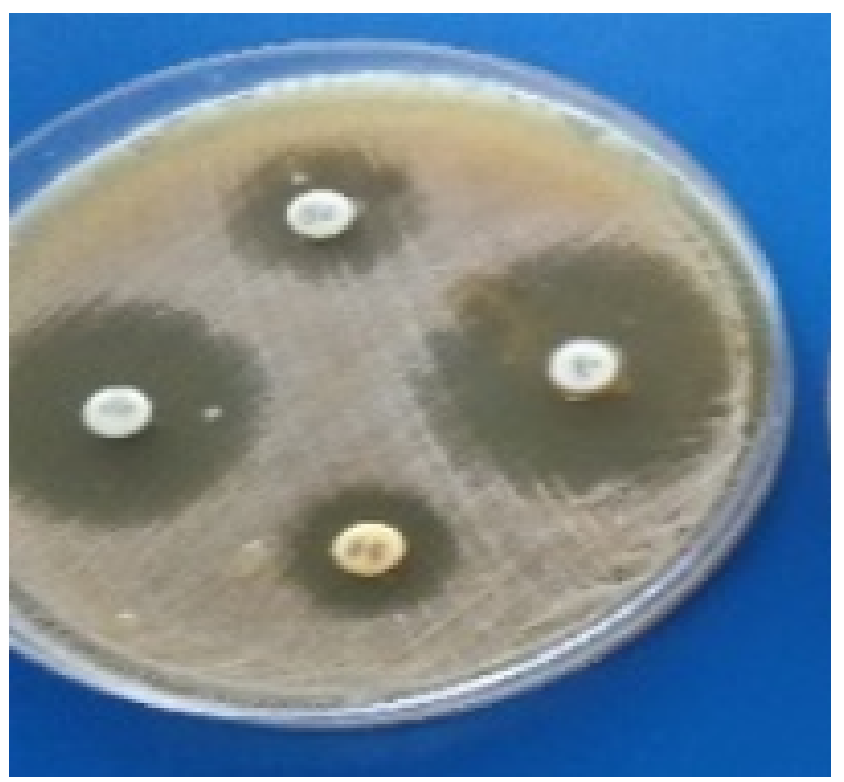

Fig. 1: Antifungal susceptibility pattern of Candida isolates on Mueller- Hinton Agar + GMB

\section{Discussion}

Candida species differ in their susceptibility to antifungal agents. On comparison of susceptibility pattern of $\mathrm{C}$. albicans and non-albicans Candida species it was observed that $\mathrm{C}$. albicans is more susceptible to all the antifungal agents tested. In the present study all the Candida albicans showed $100 \%$ susceptibility to Amphotericin-B. Similar findings were reported by other studies. ${ }^{13,14}$ It was observed that $\mathrm{C}$. albicans showed high fluconazole susceptibility rate $(95.83 \%)$ in the present study, which is consistent with other reports by Akortha et al., ${ }^{15}$ Amar etal., ${ }^{16}$ \& Pahwa et al., ${ }^{17}$ who also observed high Fluconazole susceptibility rates of $95.7 \%, 92.53 \%$ and $99 \%$ respectively. $92.53 \%$ of C. albicans were susceptible to Clotrimazole in a study by Amar et al., ${ }^{16}$ which can be compared with the present study $(93.7 \%)$. Pahwa et al., ${ }^{17}$ reported $99 \%$ of C. albicans as susceptible to Voriconazole, which can be compared with $97.91 \%$ in present study.

Among non albicans Candida spp., susceptibility to Amphotericin-B and Voriconazole varied between $83.33 \%$ to $100 \%$, Clotrimazole between $50 \%$ to $87.5 \%$ and Fluconazole between $25 \%$ to $100 \%$. Non-albicans Candida showed higher resistance to all the drugs than C. albicans. Maximum resistance was shown by C. krusei (100\%) and C. glabrata $(75 \%)$ in the present study. Findings from the present study indicate that all the isolates of $\mathrm{C}$. krusei were resistant to Fluconazole. Similar findings were shown by Hamza et al. ${ }^{18}$ Non- albicans Candida has shown an increased resistance to azoles as in other studies. ${ }^{19,20}$ Azole resistance candidiasis appears to be on the rise. The resistance to Fluconazole is of great concern because, it is most commonly used Azole for superficial as well as deepseated candidiasis. It was observed that out of the total 19 isolates which showed resistance to Fluconazole, 14 isolates were sensitive to Voriconazole. Voriconazole seemed to be superior to Fluconazole with a better susceptibility in the Fluconazole resistant strains also. This may be due to the more effective binding of Voriconazole to Cytochrome P450 isoenzyme of Candida species.

It was observed that infections with non-albicans Candida species (NAC) have shown decreased susceptibility to azole group of drugs.

\section{Conclusion}

Findings of the antifungal susceptibility test suggest that Candida spp., differ in their susceptibility to antifungal agents. On comparison of susceptibility pattern of $\mathrm{C}$. albicans and non-albicans Candida species it was observed that non-albicans Candida showed higher resistance to all the drugs than $\mathrm{C}$. albicans. Resistance to azole group of drugs was more pronounced in non-albicans candida spp. Antifungal susceptibility testing of Candida isolates will be helpful in guiding physicians to select the appropriate 
Table 1: Antifungal susceptibility pattern of Candida species.

\begin{tabular}{|c|c|c|c|c|c|c|c|c|}
\hline \multirow{2}{*}{$\begin{array}{l}\text { Candida } \\
\text { spp. }\end{array}$} & \multicolumn{2}{|c|}{ Amphotericin -B } & \multicolumn{2}{|c|}{ Clotrimazole } & \multicolumn{2}{|c|}{ Fluconazole } & \multicolumn{2}{|c|}{ Voriconazole } \\
\hline & $\mathrm{S}$ & $\mathrm{R}$ & S & $\mathrm{R}$ & $\mathrm{S}$ & $\mathrm{R}$ & $\mathrm{S}$ & $\mathrm{R}$ \\
\hline $\begin{array}{l}\text { C.albicans } \\
(\mathrm{n}=48)\end{array}$ & $48(100 \%)$ & - & $45(93.75 \%)$ & $3(6.25 \%)$ & $46(95.83 \%)$ & $2(4.16 \%)$ & $47(97.91 \%)$ & $1(2.08 \%)$ \\
\hline $\begin{array}{l}\text { C.tropicalis } \\
(\mathrm{n}=34)\end{array}$ & $32(94.11 \%)$ & $2(5.88 \%)$ & $28(82.35 \%)$ & $6(17.64 \%)$ & $28(82.35 \%)$ & $6(17.64 \%)$ & $32(94.11 \%)$ & $2(5.88 \%)$ \\
\hline $\begin{array}{l}\text { C.parapsilosis } \\
(\mathrm{n}=8)\end{array}$ & $8(100 \%)$ & - & $7(87.5 \%)$ & $1(12.5 \%)$ & $6(75 \%)$ & $2(25 \%)$ & $7(87.5 \%)$ & $1(12.5 \%)$ \\
\hline $\begin{array}{l}\text { C.krusei (n } \\
=6 \text { ) }\end{array}$ & $5(83.33 \%)$ & $1(16.66 \%)$ & $4(66.66 \%)$ & $2(33.33 \%)$ & 0 & $6(100 \%)$ & $5(83.33 \%)$ & $1(16.66 \%)$ \\
\hline $\begin{array}{l}\text { C.glabrata } \\
(\mathrm{n}=4)\end{array}$ & $4(100 \%)$ & - & $2(50 \%)$ & $2(50 \%)$ & $1(25 \%)$ & $3(75 \%)$ & $4(100 \%)$ & - \\
\hline $\begin{array}{l}\text { C.dubliniensis } \\
(\mathrm{n}=2)\end{array}$ & $2(100 \%)$ & 0 & $1(50 \%)$ & $1(50 \%)$ & $2(100 \%)$ & 0 & $2(100 \%)$ & 0 \\
\hline
\end{tabular}

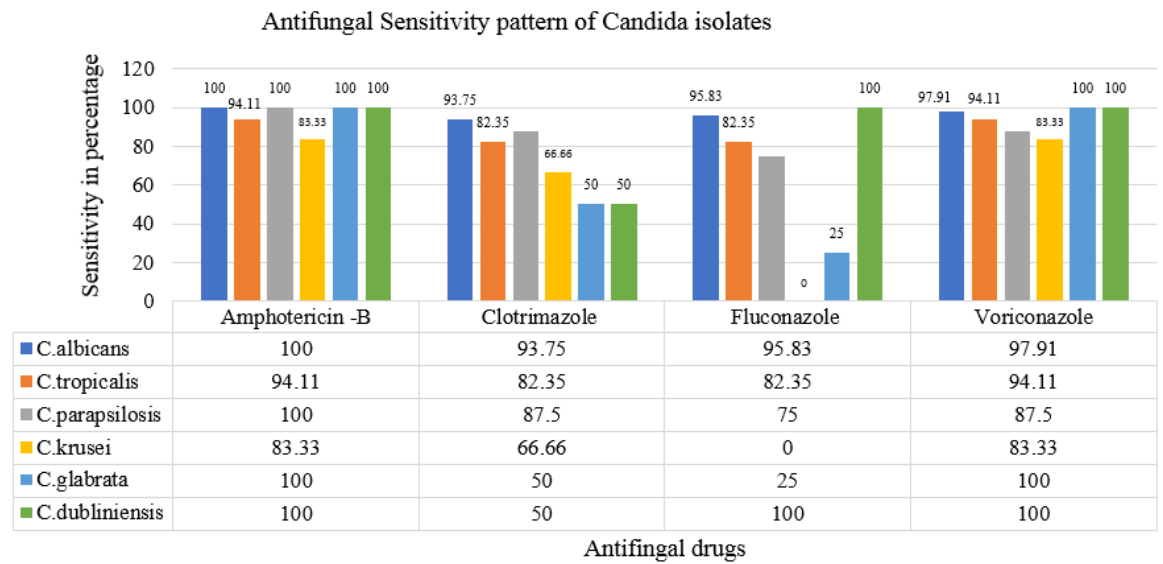

Fig. 2: Antifungal sensitivity pattern of Candida isolates

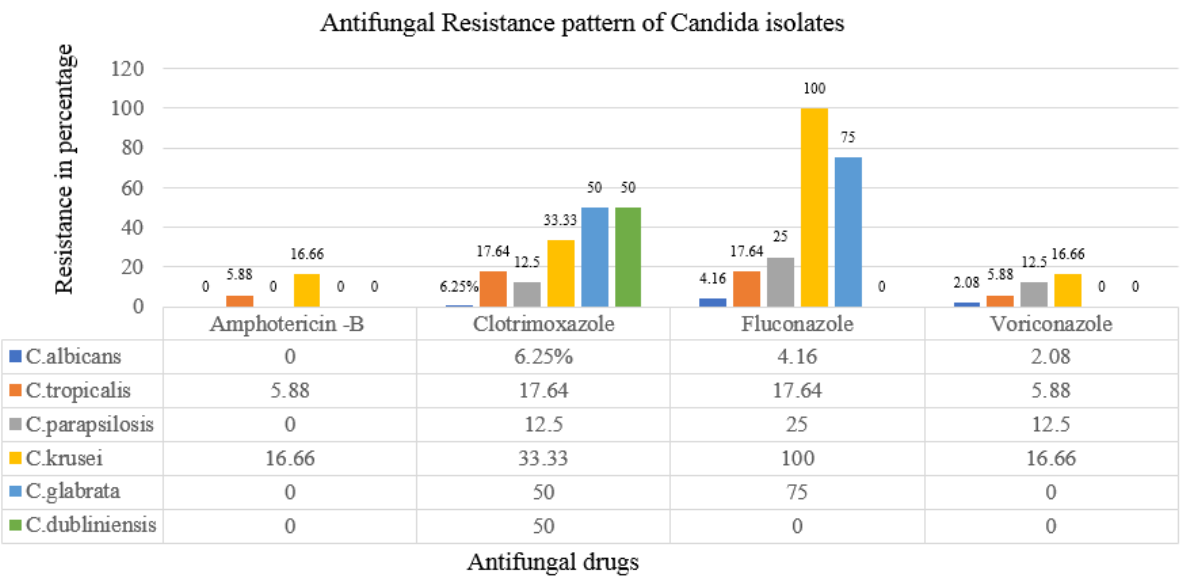

Fig. 3: Antifungal Resistance pattern of Candida isolates 
antifungal drug so that therapeutic failures can be avoided thus decreasing patient morbidity and mortality.

\section{Acknowledgement}

1. I express my heartfelt gratitude to Dr. Maimoona Mustafa, Professor and HOD, Department of Microbiology, Deccan College of Medical Sciences, Hyderabad, who has always been a source of inspiration and guidance.

2. I am thankful to the clinical and technical staff of the hospital for extending their cooperation.

\section{Conflicts of Interest}

All contributing authors declare no conflicts of interest.

\section{Source of Funding}

None.

\section{References}

1. Odds FC. Candida and Candidosis: A Review and Bibilography. In: 2nd Edn. London: Baillière Tindall; 1988.

2. Segal E, Elad D. Candidiasis. In: Topley and Wilson's Microbiology and Microbial Infections. Medical Mycology. In: Merz W, Hay RJ, editors. 10th Edn. Hodder Arnold Publishers; 2005. p. 579-623.

3. Chander J. Candidiasis. In: A textbook of Medical Mycology. In: 3rd Edn. New Delhi: Mehta Publishers; 2009. p. 266-90.

4. Greenspan D. Treatment of oral candidiasis in HIV infection. Oral

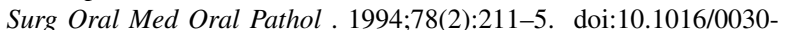
$4220(94) 90149-\mathrm{x}$

5. Baradkar VP, Mathur M, Kumar S. Hichrom candida agar for identification of candida species. Indian J Pathol Microbiol. 2010;53(1):93-5. 101:10.4103/0377-4922.59192.

6. Mane A, Panchavalli S, Bembalkar S, Rishbud A. Species distribution and antifungal susceptibility of oral Candida colonising or infecting HIV infected individuals. Indian J Med Res. 2010;131:836-8.

7. Revankar SG, Graybill JR, Patterson TF. Antifungal agents and antifungal susceptibility testing. In: Merz W, Hay RJ, editors. Topley and Wilson's Microbiology and Microbial Infections. Medical Mycology. 10th Edn. London: Hodder Arnold Publishers;. p. 147-63.

8. Matar MJ, Ostrosky-Zeichner L, Paetznick VL, Rodriguez JR, Chen E, Rex JH, et al. Correlation between E-Test, Disk Diffusion, and Microdilution Methods for Antifungal Susceptibility Testing of Fluconazole and Voriconazole. Antimicrob Agents Chemother. 2003;47(5):1647-51. 10:-10.128/aac.475. 647-165/20031.

9. Manjunath V, Vidya GS, Sharma A. Mridula Raj Prakash, Murugesh. Speciation of Candida by hicrome agar and sugar assimilation test in both hiv infected and non-infected patients. Int J Biol Med Res. 2012;3(2):1778-82.

10. Patel LR, Pethani JD, Bhatia P, Rathod SD, shah PD. Prevalence of Candida infection and its antifungal susceptibility pattern in tertiary care hospital, Ahmedabad. Natl J Med Res. 2012;2(4):439-41.

11. Mondal S, Mondal A, Pal N, Banerjee P, Kumar S, Bhargava D, et al. Species distribution and in vitro antifungal susceptibility patterns of Candida. $\quad J$ Inst Med Nepal. 2013;35(1):45-9. doi:10.3126/jiom.v3511.8897.

12. Clinical Laboratory Standards Institute (C.L.S.I.) Method for Antifungal Disk Diffusion Susceptibility of yeasts; Approved Guidelines- Second Edition. C.L.S.I. document M44-A2, Wayne, PA: Clinical and Laboratory standards Institute; 2009.

13. Dharwad S, Dominic RS. Species Identification of Candida Isolates in Various Clinical Specimens with Their Antifungal Susceptibility Patterns. J Clin Diagn Res. 2011;5(6):1177-81.

14. Vijaya D, Harsha TR, Nagaratnamma T. Candida Speciation Using Chrom Agar. J Clin Diagn Res. 2011;5(4):755-7.

15. Akortha EE, Nwaugo VO, Chikwe NO. Antifungal resistance among Candida species from patients with genitourinary tract infection isolated in Benin City, Edo state, Nigeria. Afr J Microbiol Res. 2009;3(11):694-9.

16. Sajjan AC, Mahalakshmi VV, Hajare D. Prevalence and Antifungal Susceptibility of Candida Species Isolated From Patients Attending Tertiary Care Hospital. IOSR J Dent Med Sci. 2014;13(5):44-9. doi: $109790 / 0853-13524449$

17. Pahwa N, Kumar R, Nirkhiwale S, Bandi A. Species distribution and drug susceptibility of candida in clinical isolates from a tertiary care centre at Indore. Indian J Med Microbiol. 2014;32(1):44-8. 001:0.4103/0255-085/.124300.

18. Hamza OJM, Matee MIN, Moshi MJ, Simon ENM, Mugusi F, Mikx FHM, et al. Species distribution and in vitro antifungal susceptibility of oral yeast isolates from Tanzanian HIV-infected patients with primary and recurrent oropharyngeal candidiasis. BMC Microbiol.

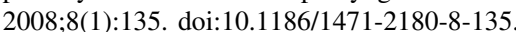

19. Devi MU, Devi KHS, Singh HL. A study on the prevalence, pattern of Antifungal susceptibility and co-relation of CD4 + T Lymphocytes amongst the Candida isolates from HIV patients in Manipur. $N J$ Basic Med Sci;2(4):329-32.

20. Deorukhar S, Saini S. Laboratory approach for diagnosis of Candida through ages. Int J Curr Microbiol App Sci. 2014;3(1):206-18.

\section{Author biography}

Ajitha Reddy Edula, Assistant Professor

Cite this article: Edula AR. Antifungal susceptibility of clinically significant candida species by disk diffusion method. IP Int J Med Microbiol Trop Dis 2021;7(2):77-80. 